\title{
Globally Controlled Robot using IoT
}

\author{
T.N.V.S.Praveen, S.Shanthi
}

\begin{abstract}
Nowadays, robots in military have become an alternative to human soldiers. Theses robots are in a position to handle different types of operations. They should be able work in different situations and areas. This paper presents the development of a robot with sensors, surveillance camera and a microcontroller. The main purpose of the robot is to prevent the terrorist attack throughout the world by monitoring and controlling of mobile robot via internet. An Arduino microcontroller board has been use of for this. The control and monitoring of robot is through an application, connected to web page. The Camera connected to the robot acts as the eye and the PIR sensor will detect the person or object that enters into the surveillance area. Whenever a suspicious person or object is found, an alarm would be generated and sent to defined authorities. These robot can be controlled from anywhere in the world by using IOT.
\end{abstract}

Keywords : Surveillance camera, PIR Sensor, Arduino microcontroller, Robot, IoT.

\section{INTRODUCTION}

Search and rescue are important operations in war. These tasks helps to save may lives. Many researches are being carried out in improvising the quality of getting information. Voice controlled robot and IR sensor robot have ability to move the robot from place to place. But, they failed to show the obstacle in their paths. Using high end surveillance camera and a microcontroller would improve the quality of these robots. The proposed system has a surveillance camera which sends the captured information a higher speed to the Arduino controller. This helps in identifying the shape and size of the object and identifies alternative paths. Infrared sensor will have both transmitter and receiver. It detects obstacle by the reflection from the object. The transmitter light falls on object and reflection from the object will be detected by Infrared detector. So, the robot will send notification through blynk app. Ultrasonic works on the echo of the sound. The ultrasonic sensor helps in finding the distance between obstacle and the robot with help of echo. The notification is provided by the ultrasonic sensor if the obstacle is detected in its path. Distance between object and robot is measured with help of formula

Revised Manuscript Received on February 05, 2020.

* Correspondence Author

T.N.V.S.Praveen*, UG Student, Department of Electronics and Communication Engineering, Saveetha School of Engineering, SIMATS, Chennai, Tamil Nadu,India Email . praveen9951939147@gmail.com

S.Shanthi, Professor, Department of Electronics and Communication Engineering, Chennai, Tamil nadu, India. Email:

shanthis.sse@saveetha.com

(c) The Authors. Published by Blue Eyes Intelligence Engineering and Sciences Publication (BEIESP). This is an open access article under the CC BY-NC-ND license (http://creativecommons.org/licenses/by-nc-nd/4.0/)

\section{Distance, D = Time X Speed of sound}

The microcontroller will have command on the robot movements. It will send information to the mobile through internet. The camera helps in finding the size of the object and also helps in seeing the overview in its surroundings.

\section{LITERATURE REVIEW}

Some of the works related to the proposed system have been discussed in this section.

Jorge Kazacos Winter,et al.[1] has developed Android Controlled Robot automation which is used to transfer information between smart phone and robot. The author has developed a robotic system, which contains wireless camera attached to it for observation. The robot has a Bluetooth to provide connection between robot and smart phone. To implement Android Controlled Robot, any system should contain Bluetooth module. It communicates information with in limited area. The information is lost when the device moves away from specified area.

R.Sindhuja,et al.[2] has told about several applications of wireless sensor networks(WSN). WSN communications can be secured but the communication patterns alone leak information. This leakage leads to serious threat. WSN do not have specific structure to transfer data. It uses nearby node for communication. WSN uses traffic normalization method to hide event locations and to transfer data. Algorithms used to implement this technique are Event filtering algorithm, Topology Approximation algorithm, Contextual Information Inference algorithm.

Tanvi G Pareek,et al.[3] explained about use of IoT in communication devices. Internet of Things is a booming technology which helps to make world automated. Class automation project is developed to automate electrical appliances such as fan, light etc. This basic architecture involves Arduino UNO connected to DC motor and LED, Blynkapp. Blynk is an user friendly platform for IoT applications. Blynk contains many widgets and it works on Bluetooth. Now-a-days, IoT is used in home appliances and automation techniques, buildings etc.

S.A. Daud,et al.[4] tells about the use of surveillance robots. Conventional robotics involves control of robots via circuits. There are many security issues by using RF technology. The traditional robots can only perform limited operations. Automated surveillance system is used in a range of real world. The robot uses gas sensors to detect gas leakage. Surveillance robot uses android smart phone to control robot, consists of micro controller, motor drivers and motors. Smartphone controlled two Axes robot for video uses wireless internet and Rasberry pi processor. 
Diksha Singh,et al.[5] explained about the use of electrical motors in robot. DC motor helps to build applications with high efficiency and low cost. The electrical speed control has high advantage when compared to mechanical speed control.

The security for the data is less if the data is transferred over RF technology. PWM pulses can be generated using Micro Controller AT89S52.

This micro controller can also be used to sense the speed of DC motor. Arduino board is used to control speed of DC motor. Arduino converts analog to digital signals.

Angalaeswari. S,et al.[6] explained about the use of robots in traffic monitoring. Modern road transport systems depends on information from the sensors. Traffic intersections between pedestrian flow and vehicle flow. The most common vehicle sensor used for vehicle detection is induction loop sensor. To overcome congestion on roads, above ground detection techniques are used. These above ground techniques make use of IR wavelengths of electromagnetic spectrum.

Kenji Nakahira,et al.[7] it tells about the working of ultrasonic sensors. Ultrasonic sensors mainly used to determine distance between two objects, it can be done by measuring time delay between sonar emissions. Each bat has a distinct emission which is strongly frequent modulated. The problem with the existing systems is that they uses constant frequency emissions. To process correlation functions in real time, many correlation techniques are used. Cost processing can be achieved using polarity correlator.

S.A. Daud,et al.[8] explained about the switching of IR sensor. IR sensor specific to Analog output, which is capable of detecting changes in distance and resolution, consists of LED, detector. To minimize noise level, the distance should be set at least $5 \mathrm{~cm}$. The output of this sensor doesn't need analog to digital converted. Cool Term stored the data from the output pin. Sensors working principle can be examined by a circuit system, which is designed to control switching IR sensors.

HIRAL S. DOSHI,et al.[9] it explains about the use of IoT in devices. IoT, has a great potential in helping human life. Many applications of IoT came into implementation. Suppose, we are injected with smart implants in our body which can analyse our blood for virus and bacteria content and sends that report to centralized system that delivers you the machine the medicine based on blood content. Main technologies to implement IoT applications are Arduino UNO, Blynk app , sensors.

Dr. Antonio Carlos Bento,et al.[10] it explains about how the research is done. Field research is used to obtain information about a problem, response is sought or discovering new phenomena between them. The field research provide detailed analysis of the problem. Question and answers, inquiries evaluate opinion on the problem. Research helps in gathering requirements, data abstraction, confronting heuristics, abstract solution.

\section{EXISTING METHOD}

In the existing systems, a robot is usually an electromechanical machine that is guided by computer and electronic programming. Many robots have been built for manufacturing purpose and can be available in industries around the world. Designing of the latest inverted robot is booming which can be controlled using an APP from android mobile. The developed remote buttons in the android app is helpful, so that we can control the robot motion. Controller can be interfaced to the Bluetooth module though UART protocol. From the commands received from android application, the robot motion can be controlled in upward, downward, front and back movements. The consistent output of a robotic system along with quality and repeatability are unmatched. Pick and Place robots are re-programmable and tools can be interchanged to provide for multiple applications. The disadvantages of the Existing system are its Complexity, unable to achieve low power consumption, Poor signal quality and Low Accuracy. Robots are controlled with the help of Bluetooth. The Bluetooth application works in the limited area. Wide range communication is not possible.

\section{PROPOSED METHOD}

Using a Smart phone as the "brain" of a robot is already an active research field with several open opportunities and promising possibilities. In the proposed system, the implementation of the approach is done in such a way that the data collection is processed in an Android mobile application. And further analysis of the collected data is carried out in order to control the robot remotely. The analysis of vibrations and any obstacles found in real time and could be processed by the Arduino and the instructions are released accordingly to control our vehicles. Ultrasonic sensor is used for obstacle detection and indicating easily. We can easily get the overall Vehicle Controls via Blue tooth Using Android Smart phones..

\section{BLOCK DIAGRAM}

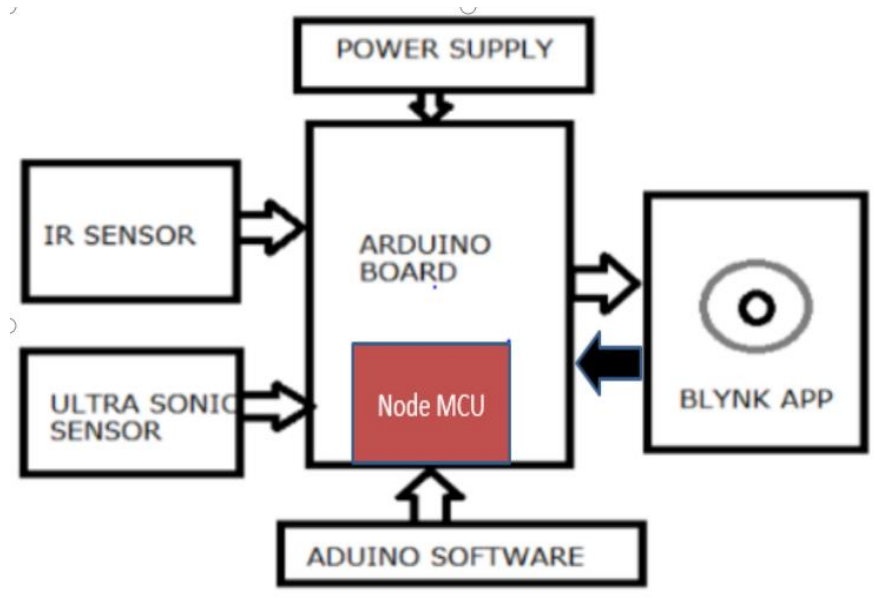

Fig.1 Block Diagram of the Proposed System

The components of the proposed system are shown in figure 1. In this project, the Arduino board plays an vital role. In Arduino board, NODEMCU is a part which is act as a WIFI module. BLYNK app is used to control the robot in path. NODEMCU is the controller board used in this project which has inbuilt WIFI module (ESP8266) which helps in communication of the control information in the module.

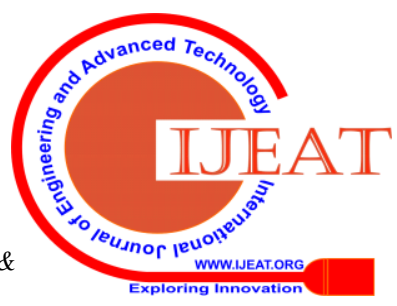


We can get access to the module globally through internet. The ultrasonic sensor acts as the important source of the module which senses any obstacle in a given range and specifies the distance between them. An IR sensor is placed in the rear of the bot which helps to detect the object at the back. Blynk app is used to monitor and control the whole bot. This app contains joystick widget through which we can control the motion of the bot. This projects help in identifying the obstacles in the path and provide the image of it. The sensors are placed at both ends of the robot. IR and UV sensors are used in detecting and the sensor helps in finding the obstacle in its path and sends the notification to the mobile device. The UV sensor works with the echo provided by it. The transmitter sends the echo and detect the obstacle with the help of receiver. The distance between robot and the obstacle can be found out with this. The camera places in robot help in identifying the size of the obstacle. The camera will work with the help of the controller unit. The microcontroller is the main station to control all the functions. Every function in the robot is monitored with the blynk app. It is user friendly for managing the functions of robot. The blynk app will provide all functions to the robot. The entire module works with internet connection. A $12 \mathrm{v}$ battery is required for the functioning of the robot and module. The internet connection should be secured and the data has to be transferred.

\section{RESULTS \& DISCUSSION}

The proposed system has been developed and tested in different environments. The performance of the proposed system has been compared in Table 1 .

Table 1. Comparison of Proposed work and Existing method.

\begin{tabular}{|c|c|c|c|}
\hline S.NO & FEATURES & $\begin{array}{l}\text { EXISTING } \\
\text { METHOD }\end{array}$ & $\begin{array}{l}\text { PROPOSED } \\
\text { METHOD }\end{array}$ \\
\hline 1 & Range & $\begin{array}{l}\text { Limited area of } \\
\text { communication }\end{array}$ & $\begin{array}{l}\text { Communication } \\
\text { can be done } \\
\text { globally }\end{array}$ \\
\hline 2 & $\begin{array}{l}\text { Channel for } \\
\text { communication }\end{array}$ & $\begin{array}{l}\text { Communication } \\
\text { through } \\
\text { Bluetooth }\end{array}$ & $\begin{array}{l}\text { Communication } \\
\text { through wif } \\
\text { and internet }\end{array}$ \\
\hline 3 & $\begin{array}{l}\text { Controlling } \\
\text { device }\end{array}$ & $\begin{array}{l}\text { Controlled } \\
\text { through } \\
\text { raspberry } \\
\text { tablet }\end{array}$ & $\begin{array}{l}\text { Controls } \\
\text { through blynk } \\
\text { app }\end{array}$ \\
\hline 4 & Frequency & $\begin{array}{ll}\text { Works with } \\
\mathrm{KHz}\end{array}$ & $\begin{array}{l}\text { Works with } \\
\text { MHz - GHz }\end{array}$ \\
\hline
\end{tabular}

In this project wifi and bluetooth module are connected to blynk app. NODEMCU will get the instructions from the blynk app. Through internet, blynk app will be operated from anywhere in the world. The use of IR and Ultrasonic sensors are used to detecting the obstacle. The final working model of the globally controlled robot is shown in figure 2 . The module has been tested in different atmospheres and scenarios. We find same results in every atmosphere. There is delay in signal in odd atmosphere like fog, cloudy conditions.

We have tested the module in the atmosphere relatively closer to coal mines. We find no delay in the signal. The module works similar to the module working with normal atmosphere. The newer machine learning techniques, data analytics and optimization methods have proven to be effective in various fields such as medical and all day to day activities, the performance of the globally controlled robot can be further improvised by incorporating these technologies [13-16].

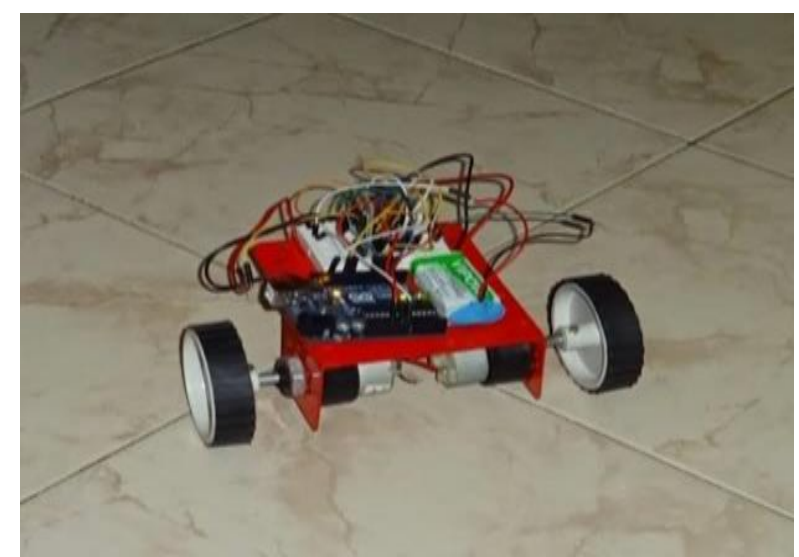

Fig.2 Working model of the Globally Controlled Robot

\section{CONCLUSION}

The robot is used in military applications and it can be controlled from any place around the globe, we can use this to intrude in opposite army camp and monitor their actions. This may also used for the industrial application. This paper mainly talks about the robots which can be controlled from anywhere in the world.

\section{REFERENCES}

1. Design of a Bluetooth Enabled Android Application for a Microcontroller Driven Robot By Vito M. Guardi,(May2014).

2. D. Cox, E. Jovanov, and A. Milenkovic, -Time synchronization for ZigBee networks, in Proc. of the Thirty-Seventh Southeastern Symposium, System Theory, pp. 135-138, 2005.

3. Piyare, Rajeev, and M. Tazil. "Bluetooth based home automation system using cell phone." Consumer Electronics (ISCE), 2011 IEEE 15th International Symposium on.IEEE, 2011.

4. T. Chin-Fu, W. Yuan-Kai, et al. "Implementation and analysis of rangefindingbased on infrared techniques." Control Conference (ASCC), 20 II 8th Asian, 20 II.

5. C. Wren, Ali Ajarbayejani, Trevor Darrel, and Alex Pantland, “P finder, Real Time Tracking of HumanBody," IEEE Trans. Pattern Analysis and Machine Intelligence, Vol. 19(7),pp. 780-785,1997.

6. R.Ranjani, R.Preethii, S.Jerine Sumitha, "Controlling the Speed of a DC Motor Using LabVIEW" International Journal of Advanced Research in Electrical, Electronics and Instrumentation Engineering, Vol. 4, Issue 12, pp.no.9463-9469, December 2015.

7. T. Chin-Fu, W. Yuan-Kai, et al. "Implementation and analysis of rangefinding based on infrared techniques." Control Conference (ASCC), 20 II 8th Asian, 20 II.

8. W. M. Masters, S. C. Jacobs, and J. A. Simmons, "The structure of echolocation sounds used by the big brown bat Eptesicus fuscus: Some consequences for echo processing," J. Acoust. Soc. Amer., vol. 89, pp. 1402-1413, 1991

9. Honeywell Sensing and Control Catalog. (2000) Series 940-942 Ultrasonic Sensors. [Online]. 


\section{Globally Controlled Robot using IoT}

10. Arduino. 2017. Site oficial. Disponível em: acesso em 28/09/2017.

11. Ashton Kevin. (2009). That 'Internet of Things' thing. Publicado no RFID Journal. Disponível em . Acesso em: 13 Mar. 2017.

12. Kuo-Hui Yeh, Senior Member, IEEE," A Secure IoT-based Healthcare System with Body Sensor Networks", IEEE Sensor Journal, 09 December 2016.

13. Shanthi, S. "Prediction of Glucose Concentration in Blood Plasma with Support Vector Regression Algorithm”, International Journal of Engineering and Advanced Technology (IJEAT), ISSN: 2249 - 8958, Volume-8 Issue-6S, August 2019.

14. S.Shanthi, ShyamalaBharathi, M.Sujatha, "Data Based Estimation of Near $\quad$ Future Values of Blood Glucose with K-Nearest Neighborhood Algorithm", International Journal of Innovative Technology and Exploring Engineering (IJITEE), ISSN: 22783075, Volume-8 Issue-12, October, 2019.

15. M. Sujatha, Shymala Bharathi, S.Shanthi, "Attendance Management System using Face Recognition", International Journal of Innovative Technology and Exploring Engineering (IJITEE), ISSN: 2278-3075, Volume-8 Issue-12, October, 2019.

16. P.ShyamalaBharathi, M. Sujatha, S.Shanthi, "Resource Allocation by Demand Based Optimization and Machine", International Journal of Innovative Technology and Exploring Engineering (IJITEE), ISSN: 2278-3075, Volume-8 Issue-12, October, 2019. 